\title{
Aplicação dos Princípios da Governança Corporativa ao Sector Público
}

\author{
Maria da Conceição da Costa Marques
}

\begin{abstract}
RESUMO
A corporate governance na perspectiva dos Estados Unidos influenciou largamente a Europa, mas não serviu assim tão bem quanto isso. A corporate governance é para assegurar que as empresas apresentam melhor performance, melhor monitorização e protecção dos investidores. No modelo anglo-saxónico, os accionistas estão longe da empresa, mas nos Estados Unidos as administrações são dominadas pela gestão, e existe algum conflito real entre o CEO (Chief Executive Officer) e o Presidente. Sob várias perspectivas, o modelo europeu é um bom modelo porque a maioria das empresas têm um grupo de accionistas que exercem uma influência directa no controlo dos negócios das empresas, mesmo que alguns não o façam. Em Portugal, esta situação requer novas estruturas e atitudes. As empresas locais ainda não quantificaram os custos de uma fraca governação. $O$ teste deste sucesso será o encaminhamento do capital para mercados onde os investidores têm confiança. Um caminho português deve ser encontrado. Neste estudo pretende-se apresentar como os princípios da corporate governance podem ser aplicados ao sector público.
\end{abstract}

Palavras-chave: corporate governance; sector público; stakeholders.

\begin{abstract}
The corporate governance from the United States (US) perspective has been highly influential in Europe, but it does not serve us well. Portugal needs to take the best of the US model, but also the best of the UK and continental European approaches. Corporate governance is about guaranteeing that companies perform well - monitoring, and protecting investors. In the Anglo-Saxon model, shareholders are remote from the company, but in the US, boards are dominated by management and there is a real confusion between the CEO and the Chairman. In many ways, the continental European model is good because the majority of companies have group shareholders who exercise direct influence and control over their affairs, so most of this does not apply. In Portugal, the situation requires new structures and attitudes, to emerge particularly in relation to minority shareholders. Local companies still do not always appreciate the costs of having poor governance. The test of its success will be that capital flows to its markets and investors have confidence. A Portuguese way must be found. In this paper we aim to present as the principles of corporate governance can be applied to public sector.
\end{abstract}

Key words: corporate governance; public sector; stakeholders. 


\section{INTRODUÇÃO}

A corporate governance (governança corporativa) começou a ser popular tardiamente, sendo bastante útil na organização de processos destinados a dirigir e atingir a accountability ${ }^{(1)}$ dentro de uma organização. Existe, no entanto, o perigo do termo poder ser usado de forma imprópria e, assim, obscurecer o seu significado

O conceito de governança corporativa está, portanto, relacionado com a accountability, cujas exigências diferem consoante a natureza da organização em causa. O termo é vantajoso para agregar um número de processos destinados a assegurar a accountability dentro das entidades públicas, tendo, numa fase inicial, a sua popularidade ocorrido no contexto do sector privado.

\section{Enquadramento Conceptual}

A corporate governance (ou governança corporativa) é um conceito relativo sobre o modo como as empresas são dirigidas e controladas. Com esta expressão pretende-se abranger os assuntos relativos ao poder de controlo e direcção de uma empresa, bem como as diferentes formas e esferas de seu exercício e os diversos interesses que, de alguma forma, estão ligados à vida das sociedades comerciais.

Entre os instrumentos de fiscalização e controlo de gestão das companhias, podem referir-se: um conjunto de deveres legais atribuídos aos administradores e accionistas controladores; a actuação independente do conselho de administração e um sistema de informação eficiente.

A governança corporativa agrega valor, apesar de, isoladamente, não ser capaz de criá-lo. Isto apenas ocorre quando ao lado de uma boa governança corporativa se possui também um negócio de qualidade, lucrativo e bem administrado. Neste caso, a boa governança permitirá um melhor desempenho, em benefício de todos os accionistas e das demais partes interessadas (stakeholders).

Nos últimos anos, a questão da governaça corporativa tem sido fortalecida por iniciativas institucionais relevantes, em vários países. Em Portugal, a Comissão do Mercado dos Valores Mobiliários (CMVM) emitiu as 'Recomendações sobre o Governo das Sociedades Cotadas em Bolsa', cuja versão originária, datada de 1999, a qual era acompanhada de uma recomendação no sentido da sua divulgação e cumprimento. Dois anos mais tarde, o Regulamento n..$^{\circ}$ 7/2001 da CMVM obrigou as sociedades emitentes de acções, admitidas à negociação em mercado 
regulamentado, à divulgação anual de informação sobre diversos aspectos ligados ao governo societário. De entre a informação a prestar nesse âmbito, salientava-se a relativa ao cumprimento das recomendações actuais ou ao seu não cumprimento e respectiva fundamentação.

Em 2003, apesar de se manterem as linhas fundamentais do Regulamento n. ${ }^{\circ} 7 /$ 2001, este voltou a ser actualizado, por forma a tornar mais completo o relatório anual sobre governo das sociedades. Paralelamente à evolução das recomendações, é de louvar que estas tenham conhecido um grau crescente de cumprimento por parte das sociedades portuguesas.

O objectivo destas recomendações é que sejam entendidas como recomendações de e para o mercado. Assim, o documento continua aberto a apreciações e sugestões e, como tal, sujeito a revisões e aditamentos.

A versão actual das recomendações da CMVM data de Novembro de 2003 e nela são incluídos aspectos como a divulgação da informação, o exercício do direito de voto e representação de accionistas, regras societárias, órgão de administração e investidores institucionais.

\section{O que é a Governança Corporativa?}

De maneira bastante genérica, a governança corporativa pode ser descrita como os mecanismos ou princípios que governam o processo decisório dentro de uma empresa. Governança corporativa é um conjunto de regras que visam minimizar os problemas de agência.

O objecto central dos sistemas de governança corporativa não é o de intervir na autonomia das organizações mas, ao contrário, pretende equilibrar a competitividade e produtividade da empresa com uma gestão responsável e transparente da mesma.

A aplicação sistemática das iniciativas legislativas, regulamentares e de autoregulação geraram uma cultura de transparência nos negócios e de gestão nas sociedades, cujos resultados se traduzem na captação de novos e melhores recursos humanos e financeiros. Ao mesmo tempo resultaram numa melhoria das suas condições, para enfrentar com maior êxito os mercados internacionais, motivando o consumo de bens e serviços, constituindo-se numa excelente carta de apresentação perante os órgãos de vigilância e controlo.

\section{Conceito}

A governança corporativa é um termo que emergiu recentemente como disciplina autónoma, ainda que as sementes deste conceito se encontrem nos anais da 
economia, da política e do direito, provenientes de séculos atrás. A importância do tema é reconhecida mundialmente, mas a terminologia e as ferramentas analíticas estão ainda a emergir, continuam a evoluir e preparam-se para se superarem dia após dia.

Assim, para este conceito, encontramos definições como as seguintes (Center for International Private Enterprise, 2002):

1. Universidad de Maryland (USM): a faculdade de compartilhar a responsabilidade da administração e a tomada de decisões importantes de uma empresa e, face da potencialidade dos seus recursos humanos, investigação, missão e orçamento.

2. Organização para a Cooperação e Desenvolvimento Económico (OCDE): governança corporativa é o sistema pelo qual as sociedades do sector público e privado são dirigidas e controladas. A estrutura da governança corporativa especifica a distribuição dos direitos e das responsabilidades entre os diversos actores da empresa, como, por exemplo, o Conselho de Administração, o Presidente e os Directores, accionistas e outros terceiros fornecedores de recursos.

3. University of New South Wales School of Economics: a definição mais restrita refere-se à forma mediante a qual uma empresa protege os interesses dos accionistas e de outros devedores. Os princípios fazem ênfase na protecção dos accionistas minoritários, visto que os grandes accionistas não precisam geralmente de protecção. Num sentido mais amplo, refere-se à responsabilidade da gerência, incluindo directores (administradores e membros das juntas directivas), perante os accionistas e perante os devedores.

4. Corporate Governance Project: a governança corporativa é um sistema interno de uma empresa mediante o qual se estabelecem directrizes que devem reger o seu exercício. A governança corporativa procura a transparência, a objectividade e a equidade no tratamento de sócios e accionistas de uma sociedade, a gestão da sua directoria, e a responsabilidade em face de terceiros fornecedores de recursos. A governança corporativa responde à vontade autónoma da pessoa jurídica, de estabelecer estes princípios para ser mais competitiva e dar garantias a todos os grupos de interesse.

\section{Princípios}

O conceito de governança corporativa foi-se desenvolvendo através de diferentes vias e um dos principias promotores do tema foi a OCDE que construiu os princípios, permitindo que se estabeleçam os seus pilares fundamentais: 
. Os direitos dos accionistas.

. O tratamento equitativo dos accionistas.

- O papel dos terceiros fornecedores de recursos.

- Acesso e transparência da informação.

- A responsabilidade da directoria e do conselho de administração.

Os princípios da OCDE tomam-se como ponto de referência para que as empresas e países desenvolvam os seus próprios princípios, obedecendo às suas particularidades e necessidades. Hoje em dia, a evolução de princípios é tão ampla que abarca outros temas, como os métodos alternativos de solução de conflitos, a responsabilidade social da empresa, as políticas de e-governance e o meio ambiente das empresas, etc.

\section{A Governança Corporativa no Sector Público}

Antes de centrarmos a nossa atenção na governança corporativa aplicável ao sector público, contemplemos a estrutura fundamental da accountability para as entidades deste sector:

Figura 1: Modelo do Processo Global de Responsabilidade no Sector Público

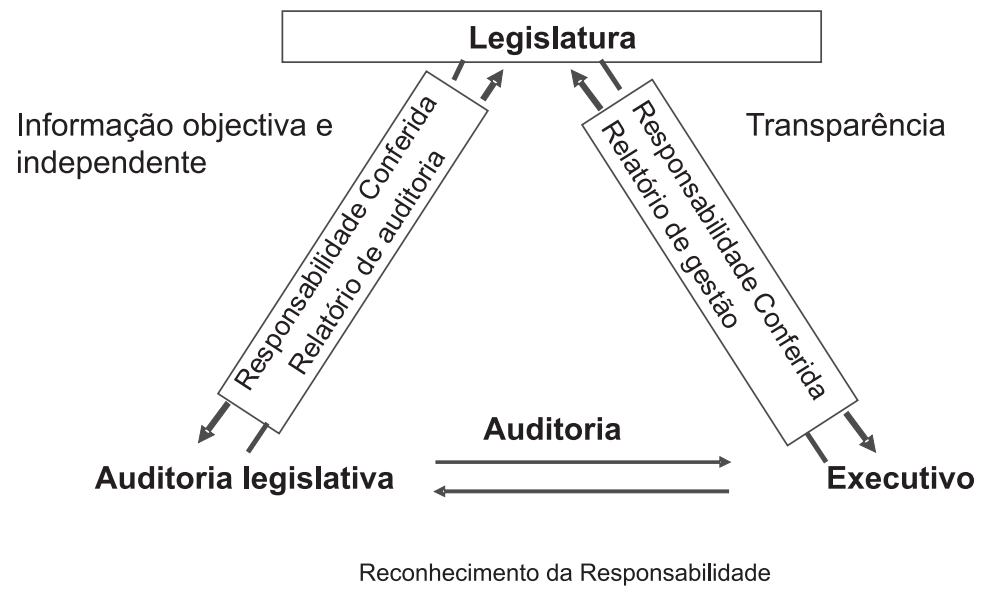

Fonte: adaptado de International Federation of Accountants - IFAC (2001).

A Figura 1 mostra a separação das funções executivas e legislativas de governo, uma vez que o Parlamento (legislatura) tem autoridade para financiar a aqui- 
sição e uso de recursos de todo o sector público, sendo o governo eleito (executivo) responsável pelos recursos específicos, planeamento, direcção e controlo das operações deste sector. A legislatura tem o direito e a responsabilidade de manter o governo responsável pela gestão e actividades. Uma das formas para viabilizar esta responsabilidade, é através de auditorias e relatórios elaborados pelo auditor legislativo (Revisores Oficiais de Contas ou empresas de auditoria).

Assim, um dos elementos da governança no sector público tem a ver com a governança pública e inclui sistemas de accountability aos ministros e ao Parlamento. O núcleo da missão, visão e os objectivos das agências públicas são também ajustados frequentemente a este nível.

É justo dizer que muitas das agências já utilizam alguns conceitos da boa governança corporativa. Estes incluem o planeamento do negócio e a estratégia, comités de auditoria, controlo de estruturas, incluindo a gestão de risco, avaliação e monitorização do desempenho (incluindo avaliação e revisão).

A Figura 2 apresenta a percepção da governança corporativa diagramaticalmente e ilustra a relação existente entre todos os elementos da governança e, assim, a necessidade de os integrar eficazmente para atingir a boa governança. Indica, também, a dificuldade de balancear todos estes elementos nalgum ponto do tempo, e a todo o tempo, e fornecer o 'mix' apropriado de conformidade e performance.

\section{Figura 2: Elementos da Governança das Entidades Públicas}

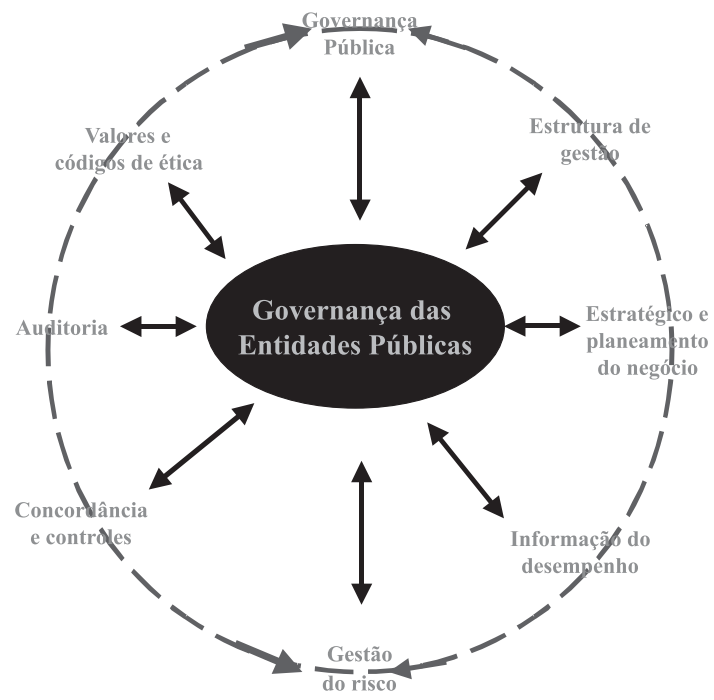

Fonte: Adaptado de ANAO, citado por Barret, P. (2003). Achieving Better Practice Corporate Governance in the Public Sector. AM Auditor General for Australia. Recuperado em 27 October, 2003, de http://www.anao.gov.au/uploads/documents/ 
Existem outras maneiras de representar a governança corporativa no sector público. De novo estas reflectem a complexidade do quadro conceptual de governança e a diversidade das aproximações feitas pelas entidades do sector público. A governança corporativa nos sectores privado e público apresenta as seguintes dimensões (Barret, 2003):

\begin{tabular}{|ll|}
\hline \multicolumn{1}{|c|}{ Missão Governança } & \multicolumn{1}{c|}{ Planeamento do Negócio } \\
Governança de posse & Múltiplos proprietários e múltiplas agências e \\
Governança estrutural & constituintes. \\
Governança estratégica & Conselhos demasiado cansados. \\
Governança da performance & Planos corporativos e de negócios. \\
Governança da concordância & Incluindo gestão de risco organizacional, \\
& individual, financeira e legal. \\
Governança da tomada de decisão & Incluindo conformidade, diligência, risco de \\
& gestão financeira e legal. \\
Governança da responsabilidade & gestão e comunicação. \\
& Proprietários e accionistas bem como \\
& stakeholders. \\
Realce do valor-capital & Incluindo sustentabilidade a longo prazo do \\
& capital corporativo, assim como "triple bottom \\
& line" (balanço final triplo) ênfase no capital \\
& financeiro, ambiental e social. \\
\hline
\end{tabular}

Não obstante o modo como esta estrutura é usada, a boa governança corporativa nos sectores público e privado requer:

. Uma clara identificação e articulação das definições de responsabilidade;

- Uma compreensão real das relações existentes entre os stakeholders (partes interessadas) da organização e outros interesses para controlar os seus recursos e dividir resultados; e

. Sustentação da gestão, particularmente do nível superior.

As auditorias mostram que é preciso mais trabalho no sector público para apresentar os elementos da governança corporativa neste sector de modo significativo, por forma que as pessoas da organização possam prontamente compreender e aceitar a sua finalidade e o modo como os vários elementos se combinam para atingir a requerida performance organizacional e a descarga das expectáveis obrigações de accountability (Barret, 2003). 


\section{O Papel da Governança Corporativa no Sector Público}

Nos Estados democráticos existem três órgãos de decisão altamente importantes: o executivo, o legislativo e o judicial. O poder dos primeiros já foi apresentado; sobre o último, é de referir que em matéria de governança pública o Tribunal de Contas detém um papel importante. Trata-se de uma instituição independente, que controla o poder executivo. Nalguns países o poder do Tribunal de Contas é mais restrito do que noutros. Mas em resultado dos grandes escândalos ocorridos nos Estados Unidos, os governos estão a impor regras que claramente separem o poder executivo das funções de auditoria. Está aqui uma área em que a governança corporativa aprendeu directamente da public governance, mas apenas depois de elevados custos (Frey, 2003, p. 21; Kaplan, 2003).

Os passos fundamentais para se atingir uma efectiva governança corporativa, segundo o Australian National Audit Office - ANAO e de acordo com a literatura existente sobre o tema (Barret, 2003) são seis, que as entidades públicas devem seguir e aplicar para atingirem as melhores práticas de governança corporativa (Figura 3). Três destes elementos - liderança, integridade e compromisso - remetem-nos para as qualidades pessoais de todos na organização. Os outros três elementos - responsabilidade, integração e transparência - são principalmente o produto das estratégias, sistemas, políticas e processos estabelecidos (Díaz Zurro, 2001, p. 21).

\section{Figura 3: Princípios de Boa Governança nas Entidades do Sector Público}

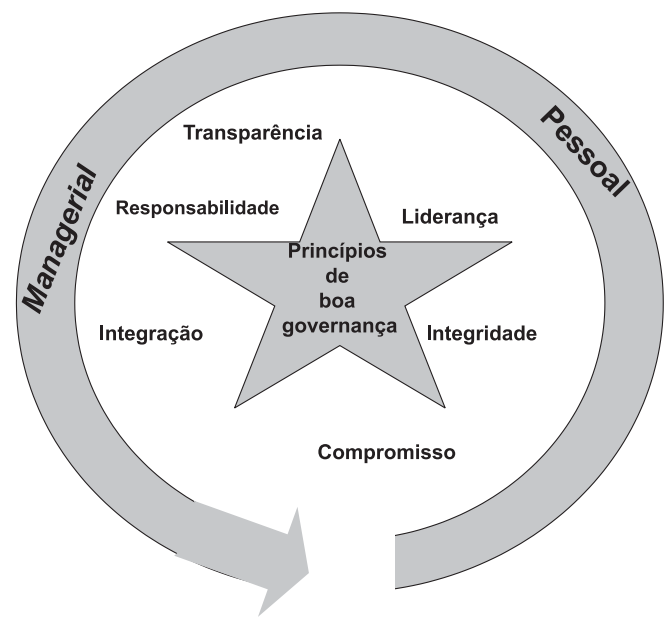

Fonte: Adaptado de ANAO, citado por Barret, P. (2003). Achieving Better Practice Corporate Governance in the Public Sector. AM Auditor General for Australia. Recuperado em 27 October, 2003, de http://www.anao.gov.au/uploads/documents/ 
Liderança - A governança do sector público requer liderança desde o governo e/ou do órgão executivo da organização. Um quadro efectivo requer a clara identificação e articulação da responsabilidade, bem como a compreensão real e apreciação das várias relações entre os stakeholder's da organização e aqueles que são responsáveis pela gestão dos recursos e obtenção dos desejados resultados (outcomes). No sector público, é necessária uma lúcida e transparente comunicação com o Ministro e é fundamental o estabelecimento de prioridades governamentais de modo claro.

Compromisso - A boa governança é muito mais do que pôr as estruturas a funcionar, pugnar pela obtenção de bons resultados e não é um fim em si mesma. As melhores práticas de governança pública requerem um forte compromisso de todos os participantes, para serem implementados $\operatorname{todos}^{(2)}$ os elementos da governança corporativa.

Isto exige uma boa orientação das pessoas, que envolve uma comunicação melhor; uma abordagem sistemática à gestão da organização; uma grande ênfase nos valores da entidade e conduta ética; gestão do risco; relacionamento com os cidadãos e os clientes e prestação de serviço de qualidade.

Integridade - A integridade tem a ver com honestidade e objectividade, assim como altos valores sobre propriedade e probidade na administração dos fundos públicos e gestão dos negócios da entidade. Ela é dependente da eficácia do controlo estabelecido e dos padrões pessoais e profissionalismo dos indivíduos dentro da organização. A integridade reflecte-se nas práticas e processos de tomada de decisão e na qualidade e credibilidade do seu relatório de performance.

Responsabilidade (accountability) - Os princípios da governança corporativa requerem de todos os envolvidos que identifiquem e articulem as suas responsabilidades e as suas relações; considerem quem é responsável por quê, perante quem, e quando; o reconhecimento da relação existente entre os stakeholders e aqueles a quem confiam a gestão dos recursos; e que apresentem resultados.

Requer também uma compreensão clara e apreciação dos papéis e responsabilidades dos participantes no quadro da governança, onde os Ministros, a Administração da entidade e o CEO são componentes chaves de uma responsabilidade saudável. $\mathrm{O}$ afastamento destes requisitos impede a organização de conseguir os seus objectivos.

Transparência - A abertura, ou a equivalente transparência, consiste em providenciar aos stakeholders a confiança no processo de tomada de decisão e nas acções de gestão das entidades públicas durante a sua actividade. Sendo aberta, através de significativos encontros com os stakeholders, com comunicações 
completas e informação segura e transparente, as acções são mais atempadas e efectivas. A transparência é também essencial para ajudar a assegurar que os corpos dirigentes são verdadeiramente responsáveis, e isso é importante para uma boa governança.

A International Federation of Accountants - IFAC (2001) realça que "a transparência é mais do que estruturas ou processos. Ela é também uma atitude e uma crença entre os intervenientes chaves, políticos, funcionários públicos e outros stakeholders, a quem a informação tem de ser exibida, e não é detida por qualquer entidade particular - ela é um recurso público, assim como o dinheiro público ou os activos".

Integração - o desafio real não é simplesmente definir os vários elementos de uma efectiva governança corporativa, mas garantir que eles estão holisticamente integrados dentro de uma abordagem da organização, pelos seus funcionários e bem compreendida e aplicada dentro das entidades. Se estiver correctamente implementada, a governança corporativa pode providenciar a integração do quadro de gestão estratégica, necessária para obter os padrões de performance de output e outcome requeridos para atingir as suas metas e objectivos.

Butler (1999) defende que nas entidades públicas a aplicação prática da governança corporativa envolve os seguintes aspectos:

. Separação dos papéis do Presidente e do Director Executivo;

. Um conselho que tenha a maioria de directores não-executivos;

. Criação de um comité de auditoria com membros não-executivos;

. Protecção da independência dos auditores externos;

. Manutenção de padrões de relatórios financeiros;

- Adopção de códigos de ética da organização;

. Instruções para conduta dos directores, que particularmente prevejam a inexistência de conflitos e divulguem os benefícios;

- Identificação do risco e gestão do risco.

Se a gestão tiver a ver com um processo de negócio, a governança diz respeito ao seu correcto desenvolvimento. O processo de governança corporativa pode ser pensado como tendo quatro actividades principais. Assim:

. Acção executiva - envolvimento em decisões executivas cruciais; 
- Direcção - Formulação da direcção estratégica para o futuro da organização a longo prazo;

. Supervisão - Monitorização e vigilância da performance da gerência; e

- Accountability - Reconhecimento das responsabilidades daqueles que legitimamente procuram pela responsabilidade.

Na literatura inglesa o tema governança corporativa é usado, por exemplo, para preparar um código de boas práticas para as autoridades governamentais. $\mathrm{O}$ termo tem-se tornado agora muito popular e em sua defesa surge, assim, filosofia associada com ele: "There is no one system of governance, in the same way as there is no one model of public administration. Nevertheless, there are likely to be some fundamental aspects that underpin a strong governance framework".

Neste estudo de 2001 (Study 13), designado Corporate Governance in the Public Sector: A Governing Body Perspective, a International Federation of Accountants (IFAC) refere que:

The public sector is complex, and public sector entities do not operate within a common legislative framework or have a standard organisational shape or size. It is important, therefore, to recognise the diversity of the public sector and the different models of governance that apply in different countries and in the different sectors, each of which has unique features that require special attention and impose different sets of accountabilities (IFAC, 2001, p. 2).

Claramente, o sector público tem responsabilidades e accountabilities perante numerosos e os mais variados stakeholders e as mais diversas exigências sobre abertura e transparência. Inversamente, o sector privado tem de ser competitivo e entregar bons resultados regularmente. A Tabela seguinte destaca algumas das principais diferenças nas estruturas típicas da governança corporativa nos sectores público e privado:

\begin{tabular}{|l|l|l|}
\hline & \multicolumn{1}{|c|}{ Sector Público } & \multicolumn{1}{c|}{ Sector Privado } \\
\hline Accountability & CEO & Conselho \\
\hline Membros do Conselho & Principalmente executivo & $\begin{array}{l}\text { Principalmente não } \\
\text { executivo }\end{array}$ \\
\hline CEO and chairman & Um e um só & Separados \\
\hline Tipo de Conselho & Por vezes composto & Unitário \\
\hline
\end{tabular}

Fonte: CPA Austrália (2002). 
Independentemente da estrutura, a boa governança corporativa requer o acordo entre as partes chaves da organização sobre os objectivos a longo prazo [por exemplo o Conselho de Gestão (incluindo o CEO) ou o CEO e a gestão (incluindo o Conselho)] (CPA Austrália, 2002).

\section{O Caso do Sector Universitário em Portugal}

\section{As Boas Práticas de Governança Corporativa}

Desde 1990 que em Portugal se têm operado significativas mudanças no funcionamento das entidades públicas, especialmente as que integram o Sector Público Administrativo (SPA). Com efeito, depois da Reforma da Administração Financeira do Estado (RAFE), iniciada naquela data, foram implementadas medidas reformadoras com o propósito de alcançar determinados objectivos, como a uniformização dos critérios de contabilização, gestão orçamental descentralizada, centralização e integração da informação, centralização dos recursos financeiros na Direcção Geral do Tesouro $^{(3)}$ e informatização de todas as etapas.

Em matéria contabilística, foi aprovado em 1997 um plano de contas específico para a Administração Pública, intitulado Plano Oficial de Contabilidade Pública (POCP), que actualmente conta com quatro planos sectoriais específicos, cujos fundamentos assentam neste plano: para a administração local, para a educação, para a saúde e para a segurança social.

No âmbito das reformas operadas, verifica-se uma nova configuração para os serviços públicos, em que o regime de autonomia administrativa constitui o modelo tipo e o regime de autonomia administrativa e financeira é entendido como regime excepcional. $\mathrm{O}$ gestor público assume um novo papel, dado que passa a deter mais competências e, concomitantemente, maior responsabilidade.

Paralelamente, verificou-se que o Tribunal de Contas operou no seu seio um conjunto de reformas, relacionadas com novas modalidades de controlo e de responsabilização. Isto é, de um controlo prévio como regra base, a ênfase agora é colocada no controlo concomitante e no controlo sucessivo da gestão.

Esta circunstância, obriga à introdução de mais e melhores práticas de governaça corporativa nas entidades públicas. Assim, são adoptadas práticas visando implementar os novos desígnios da Nova Gestão Pública (NPM), como a realização de auditorias nos serviços públicos pelo Tribunal de Contas e por empresas de auditoria, especificamente contratadas para o efeito. São adoptadas novas formas de prestação de contas. 
Ao nível das universidades, é instituída desde 1997 a prática de auditorias regulares (pelo menos de dois em dois anos), a efectuar por empresas de auditoria de reconhecido mérito, que vêm sendo realizadas e de cujas conclusões se tem retirado os melhores frutos. De facto, esta prática tem-se revelado bastante profícua, não apenas na vertente económica e financeira mas, sobretudo, ao nível do processo gestionário.

Em matéria de prestação de contas, o POCP inclui as normas e elementos que devem instruir o relato das entidades públicas que o adoptem; no entanto é o próprio Tribunal de Contas que em 2004 (Fevereiro), vem disciplinar a forma de elaboração e apresentação das contas àquele organismo. Com efeito, através da Instrução n ${ }^{\circ} 1 / 2004$, de 14 de Fevereiro, são as instituições obrigadas, não só a apresentar a documentação prevista no POCP, mas também um conjunto de informações de âmbito mais alargado, como, por exemplo, a informação sobre os fundos de maneio ${ }^{(4)}$ existentes na universidade, onde é usual o recurso a esta figura.

É igualmente instituída a apresentação de contas consolidadas por parte das universidades que, desde logo, são entendidas como grupo público. A prestação de contas consolidadas obriga, entre outros formalismos, à eliminação das transacções entre o grupo, pelo que as demonstrações financeiras consolidadas (balanço, demonstração dos resultados consolidados, relatório de gestão consolidado e o anexo ao balanço e à demonstração dos resultados por natureza consolidados), são úteis não apenas para as entidades hierarquicamente superiores e de tutela, mas também para os órgãos de governo da universidade.

\section{A Nova Lei de Autonomia Universitária}

Encontra-se já elaborado o anteprojecto da nova lei de autonomia universitária. Este anteprojecto inclui, entre outros desígnios, novas formas de governo para as instituições universitárias. Assim, o modo de designação do reitor ocorre entre os professores ou outras pessoas de reconhecido mérito habilitadas com o grau de doutor, o que se trata de uma inovação, na medida em que até agora o reitor era eleito de entre os professores catedráticos de nomeação definitiva. O reitor é coadjuvado por vice-reitores e pró-reitores por ele escolhidos nos termos da legislação vigente e dos estatutos da universidade.

Também ao nível das unidades orgânicas (faculdades), a ser aprovada a presente lei, se verificarão alterações, na medida em que o Conselho Directivo actual é substituído por um Director, exercido por um professor e coadjuvado por um ou dois subdirectores.

Acresce o facto de, actualmente, existir um decréscimo de alunos a pretenderem ingressar no ensino superior, pelo que cabe às universidades definirem a sua 
estratégia competitiva. Preocupadas com isso, estas instituições estão já a encetar medidas que visem contornar a situação.

Dentro deste espírito, a Universidade de Coimbra, viu os seus serviços administrativos e financeiros certificados de acordo com a Norma NP EN ISO 9001:2000 e em Novembro de 2004 mereceu uma menção honrosa de excelência, de acordo com os critérios do EFQM Excellence Model. O processo de certificação pela qualidade está actualmente a ser implementado em todas as unidades orgânicas desta Universidade e, seguramente, que outras instituição seguirão este trajecto de certificação pela qualidade.

Em suma, pode dizer-se que um conjunto de boas práticas de governança corporativa está a ser adoptado pelas entidades públicas portuguesas em geral, e pelas instituições universitárias em particular. Sem dúvida, que tudo isto tem em mente uma melhoria contínua do funcionamento das instituições que, acima de tudo, devem satisfazer as necessidades dos cidadãos a quem se dirigem.

\section{CONCLUSÕES}

Neste trabalho discutimos sobre a recente globalização da governança corporativa e do seu significativo desenvolvimento, visto numa perspectiva de agência.

Os cidadãos esperam uma boa governança corporativa das suas autoridades governamentais e, por isso, a sociedade reclama cada vez mais que as autoridades governamentais prestem contas. O governo é não só responsável perante o Parlamento como também perante outras partes, nomeadamente a sociedade. Esta situação é causada por todas as vertentes do progresso da sociedade, tais como o incremento no nível de educação das pessoas, acompanhado por um aumento na emancipação, dos progressos verificados no campo das tecnologias da informação, e a influência dos meios de comunicação.

É importante que um gestor no sector público saiba controlar os riscos associados à sua posição na administração pública, pelo que uma análise governamental se mostra como ferramenta útil para se alcançar isso. Este trabalho discute a forma como essa análise pode ser realizada.

Em Portugal, o sector público tem vindo a instituir práticas de governança corporativa, sendo o sector universitário um exemplo disso. Entre outras práticas, a realização de auditorias regulares nas univeridades mostra-se como uma boa experiência, pois as instituições que as têm realizado têm daí colhido os seus frutos. 
Por último, uma governança corporativa eficaz deve ser apoiada por toda a organização, desde o CEO ao Conselho, através do staff. Por outro lado, o quadro conceptual da governança corporativa da organização deve ser claramente entendido e compreendido por todos.

\section{Artigo recebido em 10.09.2004. Aprovado em 28.11.2004.}

\section{Notas}

\footnotetext{
${ }^{1}$ Accountability significa responsabilidade pela gestão.

${ }^{2}$ O sublinhado é de Barret (2003).

${ }^{3}$ Trata-se de uma Direcção Geral integrada no Ministério das Finanças, a quem cabe a centralização de todos os recursos financeiros público (espécie de banco do Estado).

${ }^{4}$ Trata-se do adiantamento de uma verba a um responsável, para fazer face a despesas urgentes e inadiáveis e de pequeno montante. No final do ano económico terá obrigatoriamente de ser regularizado.
}

\section{Referencias Bibliográficas}

Australian National Audit Office - ANAO (2002).

Performance Information in Portfolio Budget Statements (Audit Report No 18 2001-2002). Canberra: Commonwealth of Australia.

Barret, P. (2003).

Achieving Better Practice Corporate Governance in the Public Sector. AM Auditor General for Australia. Recuperado em 27 October, 2003, de http://www.anao.gov.au/uploads/ documents/

Butler, B. (1999).

Corporate Governance in the Public Sector. Annual Public Sector Symposium - Queensland, Australia, 4. Retrieved June 16, 2004, from http/ /www.cmc.qld.gov.au/library
Center for International Private Enterprise (2002).

Confecamaras. Corporate Governance. Retrieved September 23, 2004, from http/ /www.cipe.org

CPAAustralia (2002).

Inquiry into corporate governance in the victorian public sector. Retrieved May 21, 2004 from http// www.cpaaustralia.com.au

Diaz Zurro, A.

(2001). Eficiencia en la gestión y el control de la actividad economica del sector público. Revista AECA, 56(Especial XI Congreso AECA), 20-21. 
Frey, B. S. (2003).

Corporate Governance: What can we Learn From Public Governance? Institute for Empirical Research in Economics [Working Paper $n^{\circ} 166$ ]. University of Zurich.

International Federation of Accountants - IFAC (2001).

Study 13 - Corporate governance in the public sector: a governing body perspective. Retrieved August 2, 2003, from http//www.ifac.org

Kaplan, Alfredo (2003).

El Moep y el Peep, Luces Amarillas en el Tablero de las Decisiones Empresariales. VIII Congreso Internacional de Costos - Uruguay. 